\section{Chronic venous insufficiency and interest of adjustable compression wrap devices}

\author{
Knut Kroeger, ${ }^{1}$ Joachim Dissemond ${ }^{2}$ \\ ${ }^{1}$ HELIOS Klinik Krefeld; \\ ${ }^{2}$ University Hospital of Essen, Germany
}

\begin{abstract}
Adjustable compression wrap devices (ACWD) are a heterogenic group which makes it difficult to match them to individual patient in their best way, we tried to characterize these products by their technical features. We bought four different ACWD and compared them regarding construction and handling. ACWD show obvious advantages including self-management, self-application, re-adjustability and standardization of the compression therapy. Basically, all systems are one or more low stretch bandages that encircle the lower leg and adhere to itself with velcro. Some allow for a selective adjustment during the course of the application because in these systems the individual bands mutually intermesh. In others, the bandages must always be opened from proximal to distal in order to retighten individual segments. In addition only one enables the user to control the compression pressure of each segment by a built-in-pressure system. Different technical features of the four ACWDs make it difficult to compare them. For effective compression easy handling, selective adjustments and a reliable pressure control seem to be the most important aspects.
\end{abstract}

\section{Introduction}

Venous leg ulcers (VLU) are one of the most common chronic wounds in industrialized countries. ${ }^{1,2}$ VLU treatment differs fundamentally from that of PU or leg ulcer in case of DFU. Treatment of both, PU and VLU in case of DFU, focuses on relieving the pressure on the wound. In contrast, the effective and successful therapy of VLU requires an increase in pressure that can be achieved by compression therapy. ${ }^{3,4}$ This therapeutic approach is scientifically proven by numerous studies and content of all guidelines on VLU treatment. A Cochrane meta-analysis done by Nelson and Bell-Syer in 2014 also concludes that adequate compression therapy is the basis for successful treatment of VLU. ${ }^{5}$

Although compression therapy has been shown to help heal $\mathrm{VLU}^{6}$ and to reduce recurrence it is not known which interventions help people adhere to compression treatments. Weller et al. performed a Cochrane review including randomized controlled trials of interventions that aim to help people with VLU adhere to compression treatments compared to usual care. They reported that it remains unclear whether interventions like Leg Clubs ${ }^{\circledR}$ or community-based, nurse-led self-management programs improve venous ulcer healing and reduce recurrence. ${ }^{?}$

Adjustable compression wrap devices (ACWD) using hook and loop fasteners, commonly called velcro brand fasteners, present new opportunities for improving treatment outcomes, supporting patient independence and self-management in the use of compression therapy. In patients with moderate to severe lymphedema of the legs, ACWD achieved a significantly more pronounced reduction in volume after 24 hours than an inelastic multicomponent compression system (MCS). Autonomous handling of ACWD seemed to improve the clinical outcome and is a promising step toward self-management involving effective compression..$^{8,9} \mathrm{ACWD}$ is also efficient in reducing stasis edema in the elderly with prolonged immobility in the sitting position. ${ }^{10,11}$ In 40 legs from 36 patients with untreated venous edema re-adjustable ACWDs with a resting pressure of around $40 \mathrm{mmHg}$ are more effective in reducing chronic venous edema than inelastic bandages with a resting pressure of around $60 \mathrm{mmHg}$. They are also well tolerated, not only during maintenance therapy, but also in the initial decongestive treatment phase. ${ }^{12}$ In the two training courses for nurses Partsch showed that in contrast to short stretch bandages (SSB) that are frequently applied by bandagers with too low pressure, the adjustable compression wrap devices handled by the patients themselves produce more appropriate and more consistent pressure. ${ }^{13}$ This result is in line with a study from Protz et al. comparing 134 bandages with SSB including padding, 128 bandages with MCSs and 40 bandagings with ACWDs in 137 participants $^{14}$ and from Mosti et al. who demonstrated in 30 patients without arterial occlusive disease that adequate self-application of ACWD is feasible and that patents can maintain this pressure by re-adjustment. ${ }^{15} \mathrm{In}$ compliant patients, VLU randomized to nonelastic compression had a significantly faster healing rate per week than ulcers treated by the conventional four-layer compression system. ${ }^{16}$ The study analyzed healing rates in 24 extremities of 12 patients with bilateral leg ulcers randomized to have a four-layer elastic bandage in one extremity and a nonelastic compression garment
Correspondence: Knut Kroeger, HELIOS Klinik Krefeld, Lutherplatz 4047805 Krefeld, Germany.

Tel.: 02151.32-0 - Fax: 02151.32-20.40.

E-mail: knut.kroeger@helios-gesundheit.de

Key words: Chronic venous insufficiency; adjustable compression wrap devices; pressure control; readjustability.

Contributions: the authors contributed equally.

Conflict of interests: KK had received fees for oral presentations from Sanofi, UCB, Bayer, Pfizer, daiichi sankyo, medi, Hartmann, Lohmann\&Rauscher and Urgo; JD had received fees for oral presentation, consulting and scientific research from BSN medical, Paul Hartmann AG, medi, Juzo, Lohmann\&Rauscher, medi, Smith\&Nephew, Urgo.

Received for publication: 27 January 2019

Revision received: 16 June 2019.

Accepted for publication: 17 June 2019.

This work is licensed under a Creative Commons Attribution 4.0 License (by-nc 4.0).

${ }^{\circ}$ Copyright: the Author(s), 2019

Licensee PAGEPress, Italy

Veins and Lymphatics 2019; 8:8054

doi:10.4081/vl.2019.8054

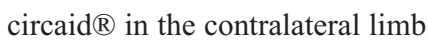

Although they are launched more than 20 years ago in the US and available in several European countries now, the body of evidence to support use of these products is small compared to the frequently used SSB or the MCS. Until today there has not been a critical evaluation of the functionality of the devices to best matching product to patient presentation and ability to use the device effectively. Unlike compression garments, which are classified by compression category (class I/II or flat knit/circular), an algorithm to direct health professionals to best match a specific ACWD to an individual patient presentation is missing. ${ }^{17,18} \mathrm{As}$ those ACWD are a heterogenic group, which makes it difficult to match them to individual patient in their best way, we tried to characterize these products by their technical features.

\section{Results}

These compression systems are fitted with velcro straps after leg application, allowing quick and easy adjustment irrespective of the therapist's experience in creating short-stretch bandages. The advan- 
tages of these systems have led to the fact that the German compression-goods manufacturers now bring these internationally existing systems known as wrap-assemblies under the name of adaptive compression wrap devices to the German market. The different models of adaptive compression wrap devices have a similar structure but nevertheless differ in their handling. Table 1 lists four adaptive compression wrap devices for the lower leg, some of which are already available in Germany or are about to be introduced, and points out the differences in their handling that are important for the patient and the doctor or nurse.

The following points should be emphasized: i) basically, all systems are one or more low stretch bandages that encircle the lower leg and adhere to itself with velcro; ii) these bandages are partly suitable for machine washing and tumble dryer; iii) under the bandage, for hygienic reasons, an underwear stocking supplied by the manufacturers should be worn; iv) an additional foot adaptive compression system is available for all systems; v) only the circaid $\AA$ juxtacures ${ }^{\circledR}$ from medi and the Compression wrap ${ }^{\circledR}$ from Juzo allow for a selective adjustment of the compression pressure during the course of the application because in these systems the individual bands mutually intermesh. In the other two systems, the bandages must always be opened from proximal to distal in order to retighten individual segments as they overlap each other like a roof tile (Figure 1); vi) medi's circaid $\AA$ juxtacures ${ }^{\circledR}$ alone enables the user to control the compression pressure of each segment by a built-in-pressure system; vii) all systems are delivered in different lengths; viii) the Ready wrap ${ }^{\circledR}$ from Lohman \& Rauscher, the JOBST ${ }^{\circledR}$ FarrowWrap ${ }^{\circledR}$ from BSN medical and the Compression wrap ${ }^{\circledR}$ from Juzo are supplied in 5 different sizes, but the available circumference sizes vary from $3 \mathrm{~cm}$ for the Juzo Compression wrap ${ }^{\circledR}$ up to $8 \mathrm{~cm}$ for the Ready wrap ${ }^{\circledR}$ from Lohman \& Rauscher. Larger reductions in circumferences in the decongestion phase, which do not exactly fit to these dimensions, can therefore not be covered by one system. This is different with medi's circaid $\AA$ juxtacures ${ }^{\circledR}$, which can be steplessly reduced from $42 \mathrm{~cm}$ to 19 $\mathrm{cm}$ in ankle size.

\section{Conclusions}

\section{ACWD show obvious advantages for the clinicians}

These advantages are self-management, self-application, re-adjustability and standardization of the compression therapy.
ACWD will find their place especially in the VLU therapy in the next few years as an alternative to the widespread compression bandages with SSB. It is even expected that in some areas they will completely replace the compression bandages with SSB, because where possible it will give the person concerned the opportunity to self-manage and where nurses will continue to be responsible for the compression therapy, a standardization of the compression therapy is available. Here, in particular, the systems that allow a control of the applied compression pressure and a simple adjustment of the compression pressure are the most important one.

\section{Pressure control is key in therapy and can only be achieved with some solutions}

The arguments for pressure control are most persuading. A recent survey on compression bandages shows that in practice the application of the frequently used SSB is time-consuming, uncomfortable and unsafe in their application, since the applied compression pressure cannot be controlled. ${ }^{19}$ MCS were found to have comparable ulcer healing rates to alternative compression systems and be easier to apply. They have similar abilities to maintain pressure as four-layer bandages and better abilities than
$\mathrm{SSB}$; have less slippage than alternative systems; and to be significantly associated with several favourable quality of life outcomes. $^{20}$ Despite these advantages Sermsathanasawadi et al. reported that only $27 \%$ of the nurses using MCS achieved subbandage pressure within the range they aimed for $(30-50 \mathrm{mmHg}){ }^{21}$ These studies demonstrate the difficulty of achieving the desired subbandage pressure and indicate that a substantial proportion of patients with VLU do not receive adequate compression therapy. ${ }^{22,23}$

\section{How to avoid complications}

In addition evidence-based guidance is needed to inform clinicians on risk factor, adverse effects, complications and contraindications. ABPI values need to be specified and details should be given on the type of compression that is safe to use. Ongoing research challenges the present recommendations, shifting some contraindications into a list of potential indications. Complications of compression can be prevented when adequate assessment is performed and clinicians are skilled in applying compression. ${ }^{24}$ In elderly patients with mixed leg ulcers and with an absolute $>60$ $\mathrm{mmHg}, \mathrm{SSB}$ of up to $40 \mathrm{mmHg}$ does not adversely affect arterial flow and appears clinically well tolerated. Such bandages
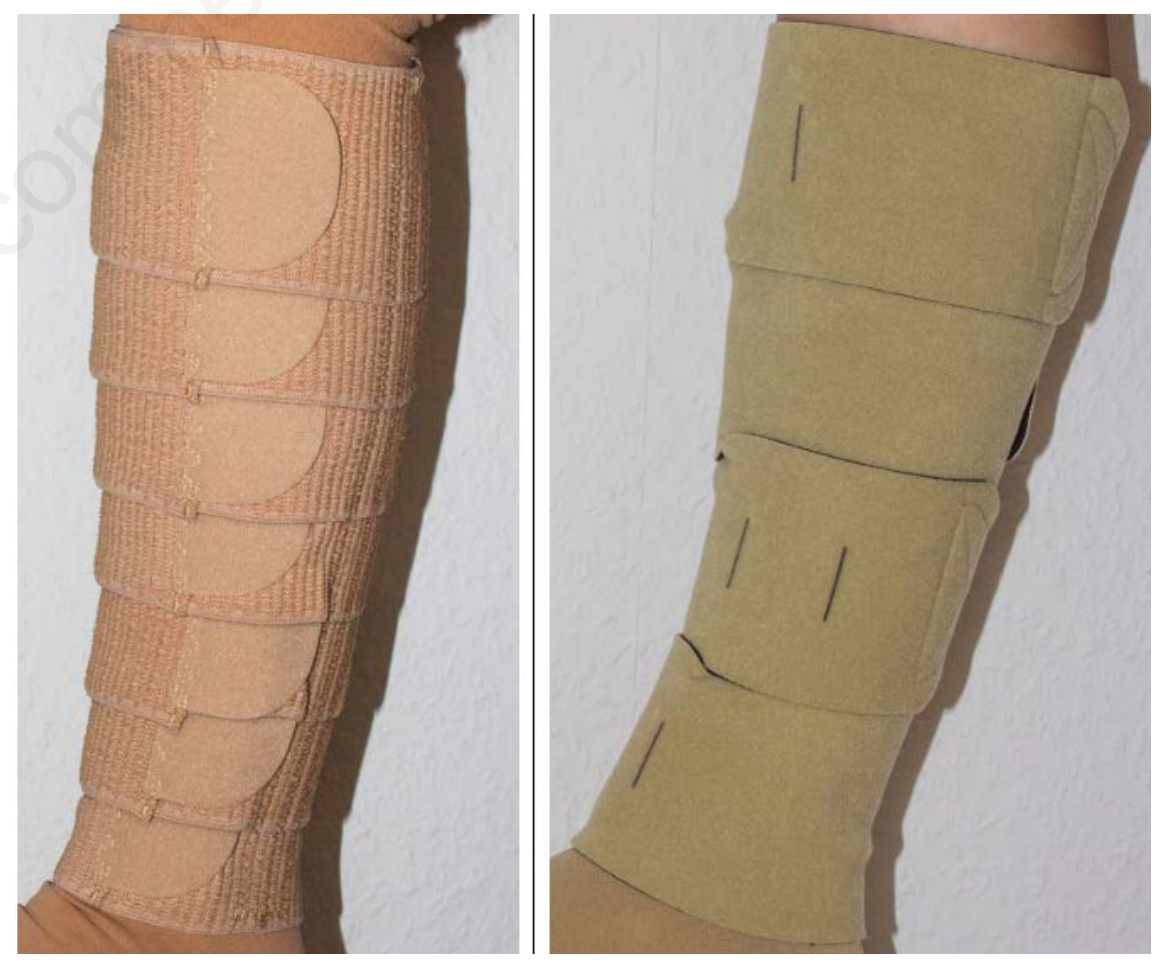

Figure 1. In those ACWD in which individual segments overlap each other like a roof tile, for retightening bandages must always be opened from proximal to distal (left). In those ACWD that are made from one piece and the individual bands mutually intermesh retightening is possible for each band without opening the complete ACWD (right). 
Table 1. The table attempts to compare the product characteristics, the possibilities of the compression pressure adjustment and the user-friendliness for four adjustable compression wrap devices for the lower leg, some of which are already available in Germany or are about to be introduced. The information is partly taken from the product information and partly from the respective German or English-language homepages of the various manufacturers.

\begin{tabular}{|c|c|c|c|c|}
\hline & $\begin{array}{l}\text { Ready wrap } \\
\text { Lohman \& } \\
\text { Rauscher }\end{array}$ & $\begin{array}{l}\text { JOBST@ FarrowWrap@ } \\
\text { BSN medical }\end{array}$ & $\begin{array}{l}\text { Circaid@ juxtacures@ } \\
\text { medi Bayreuth }\end{array}$ & $\begin{array}{l}\text { Compression Wrap } \\
\text { Juzo }\end{array}$ \\
\hline \multicolumn{5}{|c|}{ Characteristics of the products } \\
\hline Construction & 6 single sewn together bandages & 6 single sewn together bandages & In the whole one part & In the whole one part \\
\hline Sizes & $\begin{array}{l}2 \text { lengths }(30,35 \mathrm{~cm}) \\
5 \text { circumferences, each covering } 8 \mathrm{~cm} \\
\text { in the ankle and } 10 \mathrm{~cm} \\
\text { in the circumference of the wall }\end{array}$ & $\begin{array}{l}2 \text { lengths } \\
5 \text { circumferences, each covering } 5 \mathrm{~cm} \\
\text { in the ankle and } 8 \mathrm{~cm} \mathrm{l} \\
\text { in the circumference of the wall }\end{array}$ & $\begin{array}{l}3 \text { lengths }(28.33,38 \mathrm{~cm}) \\
\text { The circumference can be } \\
\text { adapted to the ankle from } \\
19 \text { to } 42 \mathrm{~cm} \text { and the calf } \\
\text { circumference from } 25 \text { to } 64 \mathrm{~cm}\end{array}$ & $\begin{array}{l}2 \text { lengths }(<40,>40 \mathrm{~cm}) \\
5 \text { circumferences, each covering } 3 \mathrm{~cm} \\
\text { in the ankle and } 6 \mathrm{~cm} \\
\text { in the circumference }\end{array}$ \\
\hline $\begin{array}{l}\text { Food compression } \\
\text { possible additionally }\end{array}$ & Yes & Yes & Yes & Yes \\
\hline \multicolumn{5}{|c|}{ Compression } \\
\hline Dosed & $? ?$ & $? ?$ & $20-30,30-40,40-50 \mathrm{mmHg}$ & $30-60 \mathrm{mmHg}$ \\
\hline Adjustable & Yes & Yes & Yes & Yes \\
\hline Controllable & No & No & Yes & No \\
\hline \multicolumn{5}{|c|}{ User-friendliness } \\
\hline $\begin{array}{l}\text { Handling of } \\
\text { readjustability }\end{array}$ & $\begin{array}{l}\text { Must be opened from } \\
\text { proximal to distal }\end{array}$ & $\begin{array}{l}\text { Must be opened from } \\
\text { proximal to distal }\end{array}$ & $\begin{array}{l}\text { Selectively adjustable } \\
\text { and controllable }\end{array}$ & Selectively adjustable \\
\hline
\end{tabular}

with appropriate levels of compression may aid ulcer healing by treating the venous part of the disease. ${ }^{25}$ In patients without disturbances of peripheral perfusion higher compression pressure leads to higher proportions of VLU healed, independent of age and could be safely preferred in older patients. ${ }^{26}$ In conclusion, we need to put more emphasis on the question if the list of contraindications for compression therapy today is still valid or if due to this list many patients remain untreated although they would benefit from compression therapy.

\section{Adherence can be improved and hence save costs}

The choice of compression system remains at the discretion of the clinicians based on evidence of effectiveness, patient tolerability, and preference. ${ }^{27}$ Adherence to compression therapy is reported to be poor, due to a number of factors, including difficulty in applying and removing the compression garments. A literature review was conducted to identify aids, equipment and other approaches to ease the application and removal of compression therapy garments. Some 12 studies were identified. Most studies focused on chronic venous insufficiency and VLU. Four methods of easing compression garment application and removal were identified: i) devices to assist in application and removal; ii) altered compression stocking design; iii) ACWD; and iv) education. ${ }^{28}$ A small pilot audit recorded the performance of the ACWD and reported in their early results that this ACWD may provide a simple, clinically effective and patientacceptable solution for self-care with compression. ${ }^{17}$ They concluded that the use ACWD could have the potential to reduce overall health-care burden by reducing necessary skilled treatment visits and/or cost while still achieving good clinical outcomes. ${ }^{18}$

Thus the improvement of VLU treatment requires an improvement in the acceptance and implementation of compression therapy and an easy and patient specific pressure control which can be achieved by ACWDs with built-in-pressure systems predominately (Table 1).

\section{Outlook}

Successful compression includes more than dosage alone. In addition to dosage, etiology and patient presentation need to be incorporated, including a patient's physical ability to use compression effectively as part of the daily routine, thereby promoting adherence. ${ }^{29}$ Although ACWDs improve acceptance and implementation of compression therapy there is a need for an individual decision for choosing specific compression devices, which can be adjusted to counteract the individual signs and symptoms in an optimally adopted way in each single patient. ${ }^{15,30}$ Future research has to define the clinical features of the most suitable patients most for different AWCD designs, the need of additional foot compression and cost effectiveness in different health systems.

\section{References}

1. Augustin M, Brocatti LK, Rustenbach SJ, et al. Cost-of-illness of leg ulcers in the community. Int Wound J 2014;11: 283-92.

2. Purwins S, Herberger K, Debus ES, et al. Cost-of-illness of chronic leg ulcers in Germany. Int Wound J 2010;7:97102.

3. Mauck KF, Asi N, Elraiyah TA, et al. Comparative systematic review and meta-analysis of compression modalities for the promotion of venous ulcer healing and reducing ulcer recurrence. J Vasc Surg 2014;60:71-90.

4. Dissemond J, Storck M, Kröger K, et al. Indications and contraindications for modern compression therapy. Wien Med Wochenschr 2018;168:228-35.

5. Nelson EA, Bell-Syer SE. Compression for preventing recurrence of venous ulcers. Cochrane Database Syst Rev 2014:CD002303.

6. O'Meara S, Cullum N, Nelson EA, et al. Compression for venous leg ulcers. Cochrane Database Syst Rev 2012: CD000265.

7. Weller CD, Buchbinder R, Johnston RV. Interventions for helping people adhere to compression treatments for venous 
leg ulceration. Cochrane Database Syst Rev 2016;3:CD008378.

8. Damstra RJ, Partsch H. Prospective, randomized, controlled trial comparing the effectiveness of adjustable compression Velcro wraps versus inelastic multicomponent compression bandages in the initial treatment of leg lymphedema. J Vasc Surg Venous Lymphat Disord 2013;1:13-9.

9. Mosti G, Cavezzi A, Partsch H, et al. Velcro compression devices are more effective than inelastic bandages in reducing venous edema in the initial treatment phase: a randomized controlled trial. Eur J Vasc Endovasc Surg 2015;50:368-74.

10. Benigni JP, Uhl JF, Balet F, et al. Evaluation of three different devices to reduce stasis edema in poorly mobile nursing home patients. Int Angiol 2018;37:322-6.

11. Benigni JP, Uhl JF, Balet F, Chahim M. Treatment protocol on stasis edema in poorly mobile nursing home patients. Int Angiol 2018;37:396-9.

12. Mosti G, Cavezzi A, Partsch H, et al. Adjustable velcro compression devices are more effective than inelastic bandages in reducing venous edema in the initial treatment phase: a randomized controlled trial. Eur J Vasc Endovasc Surg 2015;50:368-74.

13. Partsch H. Reliable self-application of short stretch leg compression: pressure measurements under self-applied, adjustable compression wraps. Phlebology 2019;34:208-13.

14. Protz K, Reich-Schupke S, Augustin M, Hagenström K. Comparison of handling, pressure and wearing comfort of different compression devices for decongestion therapy. Veins and Lymphatics 2018;7:7989.

15. Mosti G, Partsch H. Self-management by firm, non-elastic adjustable compression wrap device. Veins and Lymphatics 2017;6:7003.

16. Blecken SR, Villavicencio JL, Kao TC. Comparison of elastic versus nonelastic compression in bilateral venous ulcers: a randomized trial. J Vasc Surg 2005;42: 1150-5.

17. Ehmann S, Whitaker JC, Hampton S et al. Multinational, pilot audit of a Velcro adjustable compression wrap system for venous and lymphatic conditions. J Wound Care 2016;25:513-20.

18. Ehmann S, Bock K. Case report to demonstrate the need for selection criteria for optimal adjustable Velcro wrap prescription. J Wound Care 2018;27: S10-7.

19. Protz K, Reich-Schupke S, Klose K, et al. Compression devices for decongestion therapy: A cross-sectional observational survey of handling, pressure, and comfort. Hautarzt 2018;69:232-41.

20. Welsh L. What is the existing evidence supporting the efficacy of compression bandage systems containing both elastic and inelastic components (mixed-component systems)? A systematic review. J Clin Nurs 2017;26:1189-203.

21. Sermsathanasawadi N, Chatjaturapat C, Pianchareonsin R, et al. Use of customised pressure-guided elastic bandages to improve efficacy of compression bandaging for venous ulcers. Int Wound J 2017;14:636-40.

22. Zarchi K, Jemec GB. Delivery of compression therapy for venous leg ulcers. JAMA Dermatol 2014;150:730-6.

23. Heyer K, Protz K, Augustin M.
Compression therapy - cross-sectional observational survey about knowledge and practical treatment of specialised and non-specialised nurses and therapists. Int Wound J 2017;14:1148-53.

24. Andriessen A, Apelqvist J, Mosti G, et al. Compression therapy for venous leg ulcers: risk factors for adverse events and complications, contraindications - a review of present guidelines. J Eur Acad Dermatol Venereol 2017;31:15628.

25. Stansal A, Tella E, Yannoutsos A, et al. Supervised short-stretch compression therapy in mixed leg ulcers. J Med Vasc 2018;43:225-30.

26. Karanikolic V, Binic I, Jovanovic D, et al. The effect of age and compression strength on venous leg ulcer healing. Phlebology 2018;33:618-26.

27. De Carvalho MR, Peixoto BU, Silveira IA, et al. A meta-analysis to compare four-layer to short-stretch compression bandaging for venous leg ulcer healing. Ostomy Wound Manage 2018;64:30-7.

28. Balcombe L, Miller C, McGuiness W. Approaches to the application and removal of compression therapy: a literature review. Br J Community Nurs 2017;22:S6-14.

29. Bjork R, Ehmann S.S.T.R.I.D.E. Professional Guide to Compression Garment Selection for the Lower Extremity. J Wound Care 2019;28:1-44.

30. Bender D, Kuhn PJ, Olson DJ, Sullivan JP. Adjustable topical compression foot wrap, is more effective than a dopamine agonist, ropinirole, in reducing the symptoms of moderate to severe restless leg syndrome. Veins and Lymphatics 2016;5:5994. 